DOI: 10.1002/ ((please add manuscript number))

Article type: Full Paper

\title{
Endocytosis Mechanism of Nano Metal-organic Frameworks for Drug Delivery
}

\section{Claudia Orellana-Tavra, Sergio A. Mercado and David Fairen-Jimenez*}

Department of Chemical Engineering \& Biotechnology, University of Cambridge, CB2 3RA Cambridge. E-mail: df334@cam.ac.uk

Keywords: drug delivery, metal-organic frameworks, nanoparticles, endocytosis

We have investigated for the first time the pathway of internalization and final fate of a specific metal-organic framework (MOF) in cells. We have based our study on two calcein loaded UiO-66 samples with particles size of 150 and 260 nm (i.e. cal@ ${ }_{150} \mathrm{UiO}-66$ and cal @ ${ }_{260} \mathrm{UiO}-66$, respectively). Our study shows that the active trafficking of cal@ ${ }_{150} \mathrm{UiO}-66$ was done almost exclusively through clathrin-mediated endocytosis, whereas the uptake of cal@ ${ }_{260} \mathrm{UiO}-66$ was a combination of both clathrin and caveolae-mediated endocytosis. Co-localization studies with a lysosomal marker showed that cal@ ${ }_{150} \mathrm{UiO}-66$ was located mostly in lysosomes for further degradation, whereas cal@ ${ }_{260} \mathrm{UiO}-66$ seemed to avoid the lysosomal degradation and potentially deliver the cargo molecules in the cytosol, allowing their distribution to different cellular organelles. This study reveals the importance of the internalization processes of MOFs, particularly the relevance of their particle size, and also the critical significance of their final fate to become an efficient drug delivery system. Based on these results, it is possible that extremely small particle sized MOFs are not the most efficient carriers and instead, relatively medium size particles are required. 


\section{Introduction}

Modern society has been coping with new and complex diseases. Traditional drugs in the form of small molecules serve their therapeutic effect by circulating in the blood stream at very high concentrations. Thus, drugs are able to reach a specific organ or tissue in the desired final amount. In these conditions, healthy tissue damage, local or systemic toxicity, more frequent doses and associated side effects are however almost unavoidable. Nanomedicine has become an attractive alternative to overcome these problems by reducing the side effects of free drugs through slow release, targeted delivery, and protection from degradation. ${ }^{[1]}$ Different nano-sized preparations have been studied and some are currently in the market, including the liposome based Doxil and DaunoXome, albumin-based particles Abraxane, and PEGylated proteins such as Oncospar, PEGIntron, PEGASYS and Neulasta, demonstrating the potential of this approach. ${ }^{[2,3]}$

In this context, metal-organic frameworks (MOFs) have emerged recently as a promising alternative for drug delivery application. This is due to their particular characteristics of high pore volume, large surface areas, multiple topologies and tunable pore size and surface chemistry. ${ }^{[4,5]}$ Different therapeutic compounds have been loaded in these materials with positive results. Among others, Morris et al. have loaded and delivered the vasodilator gas nitric oxide (NO) for its use in applications such as antibacterial, antithrombotic and wound- healing $;{ }^{[6]}$ Lin et al. described the use of MOFs for the co-delivery of the anticancer cisplatin molecule and siRNA to enhance the therapeutic effect; ${ }^{[7]}$ Horcajada et al. have encapsulated several anticancer and antiviral agents into MOFs and also performed the post synthetic modification of coating a Fe-based MOF with heparin to improve its biological properties. ${ }^{[8,9]}$ One of the major advantages of these carriers compared with traditional drug delivery systems (e.g. liposomes, micelles, zeolites, mesoporous silica nanoparticles, etc.) is their high loading capacity. We have shown, carrying out a computational screening study, that MOFs can encapsulate up to $2 \mathrm{~g}$ of drug per gram of porous material, a much higher capacity than the maximum amount loaded in mesoporous silicas and organic carriers typically up to $0.3 \mathrm{mg} / \mathrm{g} \cdot{ }^{[10,11]}$ Although the fast kinetic release of drugs from crystalline MOFs still 
remains a limitation for drug delivery applications, we have demonstrated recently that amorphous MOFs can solve this issue. Indeed, we showed how by loading a drug in a MOF, followed by the collapse of the porosity around the drug through a mechanical amorphization process, it was possible to extend the drug release time from 2 to more than 30 days in systems of around $250 \mathrm{~nm}$ size, small enough to cross the cell membrane. ${ }^{[12]}$

In order to develop efficient and successful MOF systems for drug delivery it is not only important to study the loading and release of different therapeutic compounds, but also to understand the mechanisms of cellular uptake and intracellular fate. Molecules generally enter cells by passive diffusion, whereas nanoparticles usually need an energy dependent method called endocytosis. ${ }^{[13,14]}$ This cellular mechanism has attracted the attention of many scientists within the field. However, different research groups have shown that establishing general rules for the optimization of the cellular internalization of particles is a complex task due to a variety of factors. These factors include the rate and endocytic pathway selection, which is extremely cell line dependent, and specific characteristics of the materials, such as size, shape, surface charge and surface chemistry. ${ }^{[15,16]}$ For example, Chithrani et al. demonstrated that the uptake of gold nanoparticles of $50 \mathrm{~nm}$ was more efficient than smaller or larger particles on HeLa cells. ${ }^{[17]}$ On the other hand, Win et al. showed that polystyrene nanoparticles of $100 \mathrm{~nm}$ were internalized more efficiently than the 50 and $200 \mathrm{~nm}$ particles on adenocarcinoma cells. ${ }^{[18]}$ Understanding the different mechanism of endocytosis and how MOFs interact with the cellular membrane and finally enter cells is therefore a key task for optimizing drug delivery systems.

When studying the cellular uptake, we can define two types: phagocytosis (i.e. "cell eating”) and pinocytosis (i.e. "cell drinking”), more commonly known also as endocytosis. ${ }^{[19]}$ The former refers to the process of engulfing foreign large particles $(>0.5 \mu \mathrm{m})$ and is carried out by the phagocytosis specialists, macrophages and neutrophils, ${ }^{[20]}$ whereas pinocytosis is used for internalizing fluid surrounding the cell and thus all the molecules and small particles in the fluid phase. ${ }^{[15]}$ In turn, there are 3 main endocytosis pathways which are classified depending on the 
proteins involved: i) clathrin, ii) caveolae, and iii) clathrin and caveolae-independent endocytosis such as macropinocytosis. ${ }^{[19,20]}$ Clathrin-mediated endocytosis is the most understood metabolic pathway, where cellular receptors recognize and internalize particles into 60-200 nm protein (clathrin) coated vesicles called early endosomes. These endosomes become mature vesicles or late endosomes that fuse with lysosomes, provoking the degradation of the drug delivery system and potentially the loaded cargo, thus undermining or totally voiding its therapeutic effect. On the other hand, caveolae-mediated endocytosis is related to the clustering of lipid rafts forming flask shape invaginations in the cell membrane. Finally, in clathrin and caveolae-independent endocytosis, the cargo is absorbed through $0.5-1.0 \mu \mathrm{m}$ vesicles in a non-specific way, and is therefore found in almost all cells types. ${ }^{[13]}$ Understanding the factors that affect the endocytosis mechanism of MOFs is critical to design new drug delivery systems able to avoid lysosomal degratation that may prevent the MOF and drug action before degradation.

In this work, we aim to understand the trafficking mechanism and possible fate of MOFs after cellular internalization, as well as proposing the set-up of techniques and parameters for these studies using MOFs. Here, we used a calcein loaded Zr-based MOF, UiO-66 (UiO = University of Oslo), which has been used by others and ourselves as a drug delivery vehicle for the release of different drugs into cells. ${ }^{[12,21,22]}$ We studied the different endocytosis pathways for the uptake of two different UiO-66 samples with different particle size by HeLa cells, a tumoral cervical epithelial culture frequently used for in vitro studies, in the presence and absence of different endocytosis pharmacological inhibitors. We used Fluorescence-Activated Cell Sorting (FACS) to measure the internal cellular fluorescence, followed by confocal microscopy to determine the intracellular location of the loaded UiO-66.

\section{Results and Discussion}

We choose UiO-66, $\left[\mathrm{Zr}_{6} \mathrm{O}_{4}(\mathrm{OH})_{4}(\mathrm{BDC})_{6}\right](\mathrm{BDC}=1$,4-benzenedicarboxylate $)$, in this study because of the low toxicity of $\mathrm{Zr}$. Indeed, zirconyl acetate shows a lethal dose, $\mathrm{LD}_{50}$, of ca. $4.1 \mathrm{mg} / \mathrm{ml}$ in rats; the human body contains ca. $300 \mathrm{mg}$ of $\mathrm{Zr}$, and the daily amount ingested is ca. $3.5 \mathrm{mg} /$ day. ${ }^{[23]}$ 
Additionally, we have seen that $\mathrm{IC}_{50}$ value for UiO-66 on HeLa cells is $1.503 \pm 0.154 \mathrm{mg} / \mathrm{mL}$ after 24 hours of exposure. ${ }^{[12]}$ UiO-66 has a cubic structure based on $\mathrm{Zr}$ oxo-clusters and BDC ligands, and possesses high thermal and chemical stability combined with a large porosity $\left(\mathrm{S}_{\mathrm{BET}}=1200 \mathrm{~m}^{2} \mathrm{~g}^{-}\right.$ ${ }^{1}, \mathrm{~V}_{\mathrm{p}}=0.5 \mathrm{~cm}^{3} \mathrm{~g}^{-1}$ ) formed by two main cavities of ca. 11 and $8 \AA$ diameter. ${ }^{[12,24-26]}$ In this work, we used two different protocols for UiO-66 synthesis in order to obtain two samples with different particle size. In order to analyze the endocytosis mechanism used by HeLa cells to incorporate UiO66, we loaded the two UiO-66 samples with a fluorescent molecule, calcein. We chose this molecule as a model because it can be easily detected by FACS and confocal microscopy. Also, it is hydrophilic, so it cannot cross the cell membrane and consequently it requires a drug delivery system to be transported inside the cells. Due to its self-quenching characteristics, high local concentrations of calcein (e.g. as loaded in a MOF before being delivered) cannot be detected, and therefore will only be observed when is released from the solid. ${ }^{[27]}$ This last characteristic do not interfere with any of the experiments shown in this work as the kinetics of calcein release from this material are fast, reason why it is possible to observe the calcein signal after 2 hours of incubation. Figure S1 (electronic supporting information, ESI) shows the powder X-ray diffraction (PXRD) pattern of both synthesized UiO-66 and calcein loaded UiO-66 samples, confirming the crystalline structure before and after the loading. Figure S2 shows the scanning electron microscopy (SEM) images, indicating a particle size of $153 \pm 2$ and $261 \pm 7 \mathrm{~nm}$ for both samples, named here ${ }_{150} \mathrm{UiO}$ 66 and ${ }_{260} \mathrm{UiO}-66$, respectively. Additionally, the colloidal characterization of the particles was determined in growth media and PBS (ESI, S3). The measurements showed a particle size of $156 \pm$ 6 and $275 \pm 53 \mathrm{~nm}$ for ${ }_{150} \mathrm{UiO}-66$ and ${ }_{260} \mathrm{UiO}-66$ in growth media, respectively. This confirms that the particles maintained the same particle size range in the solution where the experiments were performed. The themogravimetric analysis (TGA) of UiO-66 (Figure S4) showed a first step at 100 ${ }^{\circ} \mathrm{C}$ corresponding to the solvent molecules desorption, followed by the solid degradation at $450{ }^{\circ} \mathrm{C}$. Additionally, the calcein loaded materials, denoted as cal@ ${ }_{150} \mathrm{UiO}-66$ and cal@260UiO-66, presented another step at ca. $350^{\circ} \mathrm{C}$ corresponding to calcein leaving the solid. The amount of 
calcein loaded in the materials was ca. 7 and $10 \pm 2$ wt.\% for ${ }_{150} \mathrm{UiO}-66$ and ${ }_{260} \mathrm{UiO}-66$ respectively. It is important to emphasize that in order to have comparable results between both UiO-66 samples in the following experiments, the amount of calcein used was either the same for both samples or the results were normalized with respect to the control sample. This means that the results are not affected by the different fluorescent intensities of the samples.

\subsection{Evaluation of energy dependence}

In order to asses if the internalization of UiO-66 was an energy dependent process, i.e. endocytosis, rather than passive diffusion, we incubated the HeLa cells with either cal@ ${ }_{150} \mathrm{UiO}-66$ or cal ${ }_{260} \mathrm{UiO}-66$ at $37{ }^{\circ} \mathrm{C}$ and $4{ }^{\circ} \mathrm{C}$. It is well know that many proteins and metabolic pathways are sensitive to temperature, and therefore active processes are reduced at low temperature. ${ }^{[31]}$ Figure 1 shows the comparison of internal fluorescence, measured by FACS, of HeLa cells incubated with cal@ @150UiO-66 and cal $@_{260} \mathrm{UiO}-66$ at $37{ }^{\circ} \mathrm{C}$ and $4{ }^{\circ} \mathrm{C}$. The internalization of both UiO-66 samples was greatly inhibited at low temperature, and the uptake was ca. $75 \%$ lower than the control (at $37^{\circ} \mathrm{C}$ ). This result confirms that the uptake mechanism used by cells for the internalizing the MOF particles is through endocytosis and not by simple passive diffusion. Similar results have been reported for other types of nanoparticles such us silicas and carboxylated polystyrene nanoparticles. ${ }^{[28-30]}$

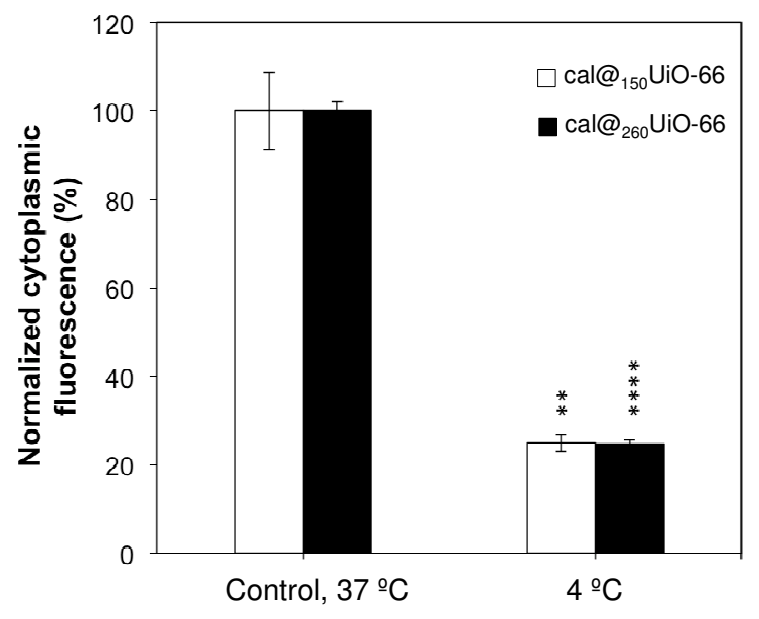

Figure 1. Effect of temperature $\left(37{ }^{\circ} \mathrm{C}\right.$, control, and $\left.4{ }^{\circ} \mathrm{C}\right)$ on cal@ ${ }_{150} \mathrm{UiO}-66$ and cal@ ${ }_{260} \mathrm{UiO}-66$ uptake after $1.5 \mathrm{~h}$ incubation, measured by FACS. The statistical significance was determined by using Student's $\mathrm{t}$ test, and is indicated in the graph: **P $<0.01, * * * * \mathrm{P}<0.0001$. 


\subsection{Effect of different endocytosis inhibitors on the uptake of cal@UiO-66}

We then evaluated the effect of different pharmacological inhibitors in order to understand the endocytic pathway used for HeLa cells on the uptake of UiO-66. First, we used sucrose and chlorpromazine to inhibit clathrin-mediated endocytosis. Sucrose is involved in the dispersion of clathrin matrices on the cell membrane, whereas chlorpromazine inhibits clathrin disassembly and receptor recycling to the membrane during clathrin-mediated endocytosis. ${ }^{[30,31]}$ Second, we used nystatin, a polyene antibiotic, for preventing caveolae-mediated endocytosis by sequestration of cholesterol from the cell membrane. ${ }^{[31]}$ Third, rottlerin was employed to avoid intake by micropinocytosis through inhibition of kinases proteins. ${ }^{[32]}$ As positive controls for the inhibitors, we used specific tracers proven to selectively enter into cell through a specific pathway: transferrin and ceramide for clathrin and caveolae-mediated endocytosis, respectively, and dextran for macropinocytosis. ${ }^{[30,33]}$ We evaluated the uptake of UiO-66 in the presence of the inhibitors after a short exposure time $(2 \mathrm{~h})$ as confusing results may be generated when longer periods are used. This is because the inhibition of one endocytic pathway may activate compensatory uptake mechanisms, as has been reported previously. ${ }^{[31]}$ Also, metabolic processes and membrane integrity in unhealthy cells would be altered and therefore the results may induce artifacts, so it is important to work in a concentration range where cells are not going to suffer any damage. To define suitable working concentrations, cytotoxicity analyses were carried out after $2 \mathrm{~h}$ of exposure to the inhibitors.

Figure 2 shows the metabolic activity of HeLa cells after $2 \mathrm{~h}$ of exposure to the different pharmacological endocytosis inhibitors measured by the bioreduction of a tetrazolium compound (MTS) into a formazan colored product, known as MTS assay. According to this, we established the working concentrations for sucrose and nystatin as $102.7 \mathrm{mg} / \mathrm{mL}(0.3 \mathrm{M})$ and $250 \mu \mathrm{g} / \mathrm{mL}$ respectively. These values were selected based on the values found in literature for this kind of experiments, as these two compounds did not present a negative effect on cell viability in the concentration range tested. ${ }^{[31,33,34]}$ The concentrations for chlorpromazine and rottlerin were set at 
$31.9 \mu \mathrm{g} / \mathrm{mL}(100 \mu \mathrm{M})$ and $2.6 \mu \mathrm{g} / \mathrm{mL}(5 \mu \mathrm{M})$, respectively. In this case, we selected the maximum concentration that exhibits the lowest detrimental effect on cell viability.

a)

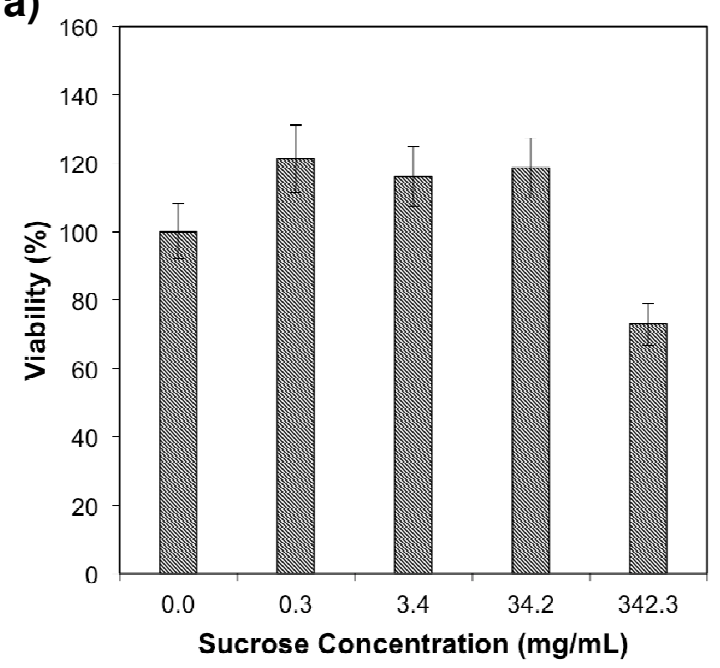

c)

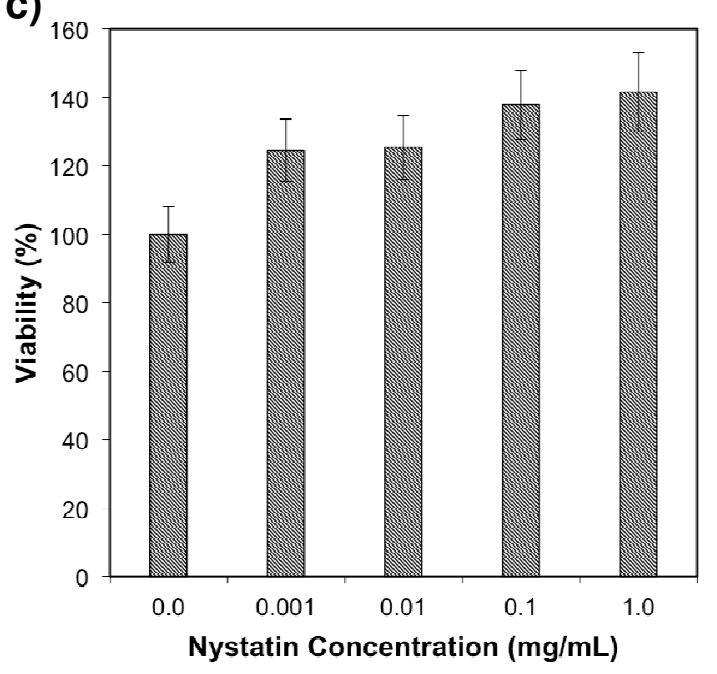

b)

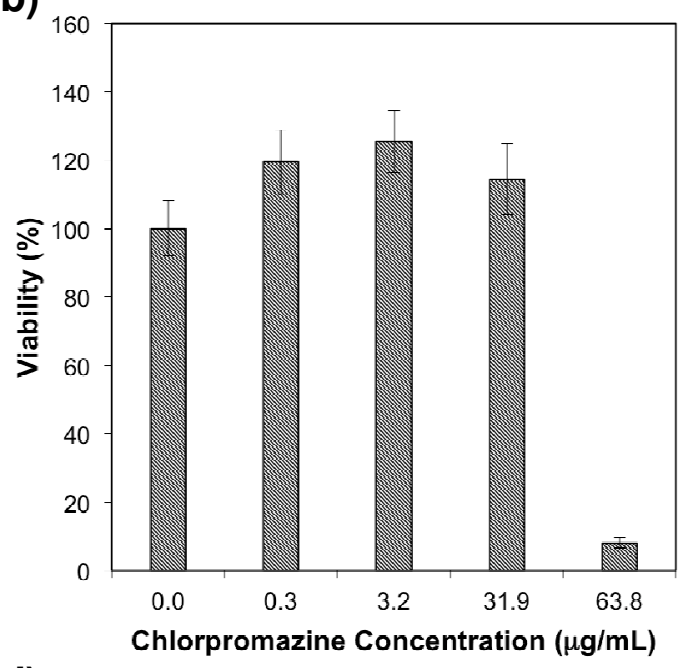

d)

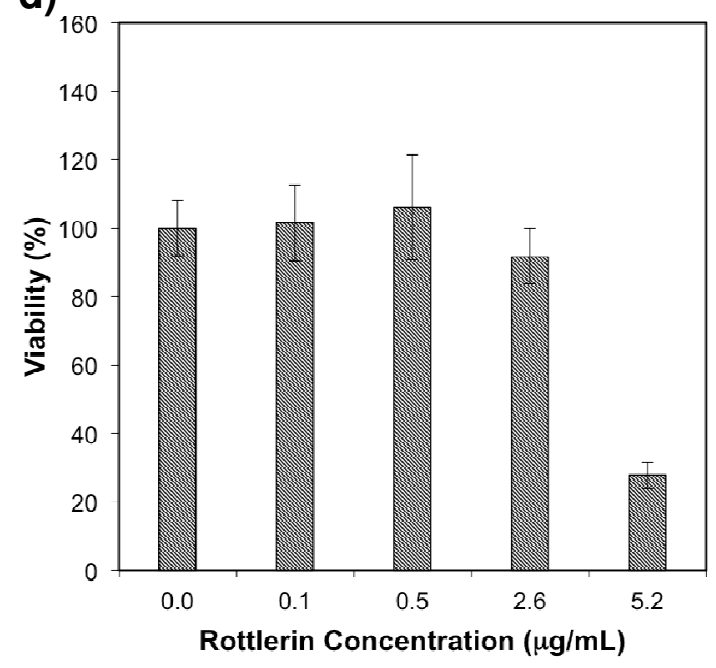

Figure 2. Metabolic activity of HeLa cells after $2 \mathrm{~h}$ of exposure to different pharmacological endocytosis inhibitors measured by MTS assay: a) sucrose, b) chlorpromazine, c) nystatin, and d) rottlerin.

Figure 3 shows the normalized internal fluorescence, obtained through FACS, of HeLa cells after the uptake of the two UiO-66 samples with different particle size in the presence of inhibitors. The uptake of cal@ ${ }_{150} \mathrm{UiO}-66$ after exposure to sucrose and chlorpromazine (i.e. clathrin-mediated endocytosis inhibitors) was $20 \%$, whereas exposure to nystatin (i.e. caveolae-mediated endocytosis inhibitor) had a minor effect (ca. $89 \%$ ), and rottlerin (i.e. micropinocytosis inhibitor) decreased the uptake to ca. $42 \%$. For cal@ $@_{260} \mathrm{UiO}-66$, the uptake after the exposure to sucrose and chlorpromazine decreased to ca. 46 and $59 \%$, respectively, whereas nystatin and rottlerin inhibited 
the uptake to ca. $79 \%$ and $64 \%$, respectively. The decrease on uptake to $20 \%$ when blocking the clathrin-mediated process suggests that the trafficking of small cal@150UiO-66 particles are following this pathway, whereas there was no statistical difference with control cells when caveolae-mediated endocytosis was inhibited. On the contrary, cal@ ${ }_{260} \mathrm{UiO}-66$ uptake was highly inhibited when both caveolae- and clathrin-mediated endocytosis were blocked. These results indicate that the UiO-66 internalization pathway is affected by the size of the particles: the trafficking of cal@ ${ }_{150} \mathrm{UiO}-66$ is done almost exclusively through the clathrin pathway, whereas the internalization of cal@ ${ }_{260} \mathrm{UiO}-66$ is a combination of both clathrin and caveolae-mediated endocytosis. In addition, part of the trafficking for UiO-66 with both particle sizes is made through macropinocytosis, as the internalization is affected by the presence of rottlerin. Nevertheless, this is a non-selective mechanism to internalize large quantities of solution, independently of the cargo. ${ }^{\text {[35] }}$

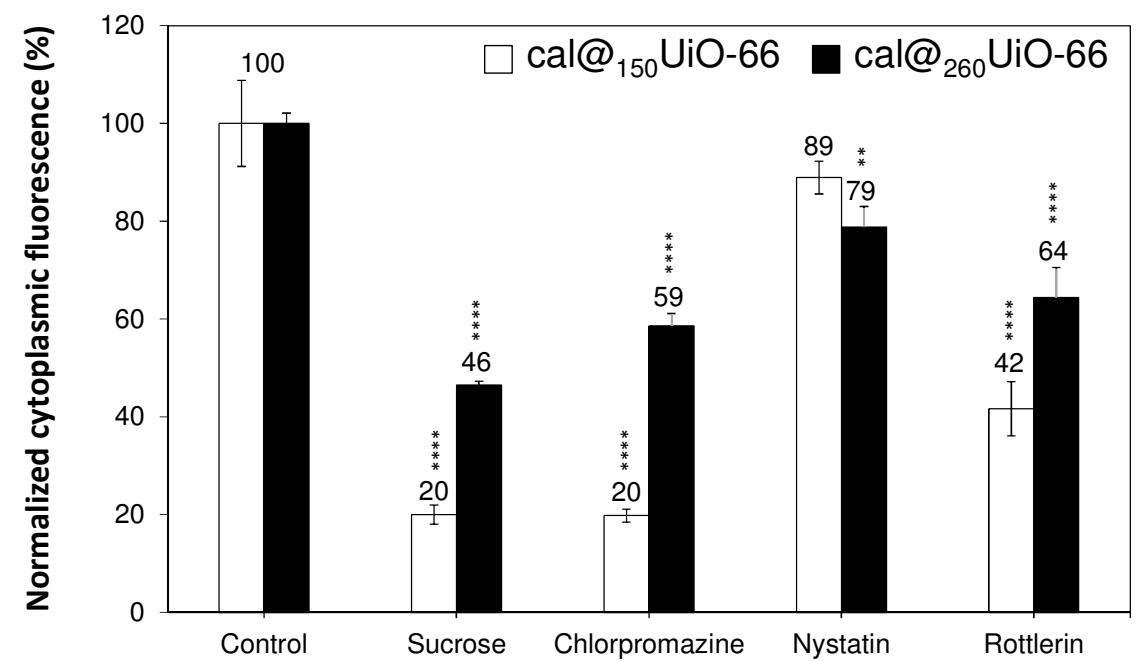

Figure 3. Effects of pharmacological endocytosis inhibitors on the uptake of cal@ ${ }_{150} \mathrm{UiO}-66$ and cal@ ${ }_{260} \mathrm{UiO}-66$, measured by FACS. The statistical significance was determined by using ordinary one-way ANOVA, and is indicated in the graph: $(* * \mathrm{P}<0.01, * * * * \mathrm{P}<0.0001)$.

\subsection{Effect of incubation time on the uptake of cal@UiO-66}

Since the uptake kinetics of clathrin-mediated endocytosis is faster than caveolae-mediated, we wanted to study the effect of incubation time in order to support our endocytic pathway usage analysis. Figure 4a shows the internal fluorescence values for both UiO-66 samples with different particle size during a time frame between $15 \mathrm{~min}$ and $3 \mathrm{~h}$, whereas Figure $4 \mathrm{~b}$ represents the 
normalized uptake values with respect to the $3 \mathrm{~h}$ uptake. As expected, the internalization of UiO-66 of both particle sizes was time dependent, showing a positive trend on the values of internal fluorescence over time. The cellular uptake efficiency (i.e. the total amount) for cal @ $260 \mathrm{UiO}-66$ was higher than for cal @ ${ }_{150} \mathrm{UiO}-66$ for all the times measured (Figure 4a). This was independent from the fact that in the experiments the amount of ${ }_{150} \mathrm{UiO}-66$ was higher than ${ }_{260} \mathrm{UiO}-66$ in order to keep the same amount of calcein in both samples and to be able to compare both results. Nevertheless, cal@ ${ }_{150}$ UiO-66 was internalized faster than cal@ ${ }_{260}$ UiO-66 (Figure 4b). Indeed, the uptake of cal@ ${ }_{150} \mathrm{UiO}-66$ was ca. $60 \%$ at 30 min, whereas cal@ $@_{260} \mathrm{UiO}-66$ reaches this value after 2 h. These results based on the kinetics of the endocytosis process further support the clathrin-mediated route for cal@ ${ }_{150} \mathrm{UiO}-66$, whereas the caveolae-mediated route plays an important role for cal@ ${ }_{260} \mathrm{UiO}$ 66.
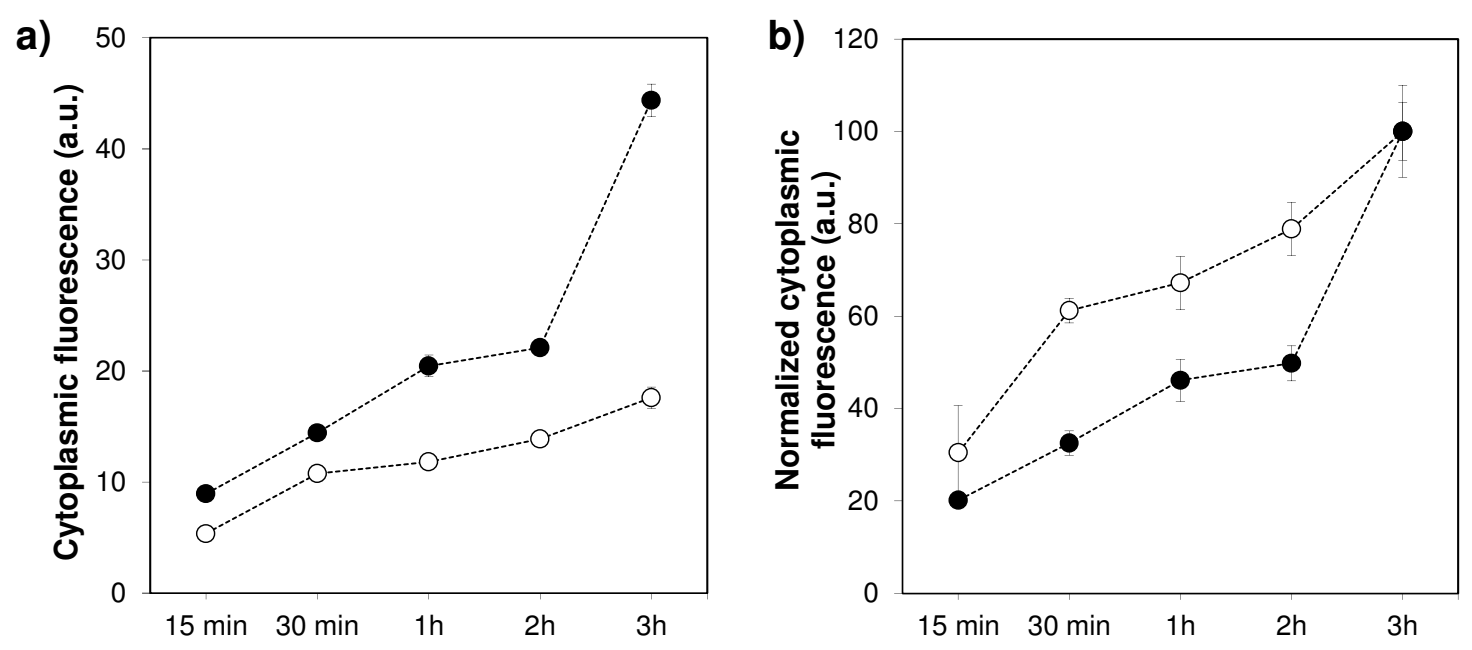

Figure 4. Kinetics of cal@ ${ }_{150} \mathrm{UiO}-66$, open circles, and cal@ $@_{260} \mathrm{UiO}-66$, black circles, uptake measured by FACS. a) Cytosolic fluorescence after incubation for different times, and b) normalized values, where fluorescence of cells treated for $3 \mathrm{~h}$ was considered as $100 \%$.

\subsection{Intracellular localization of UiO-66 by using endocytic tracers}

We used laser confocal microscopy to determine if the loaded UiO-66 particles were located in the same intracellular vesicles as some specific tracers well known for their preferential endocytic pathway selection: transferrin, ceramide and dextran to stain clathrin-mediated endocytosis, caveolae-mediated endocytosis and macropinocytosis vesicles, respectively. Figures $5 \mathrm{a}$ and $5 \mathrm{~b}$ 
show the confocal images of Hela cells incubated with cal@ ${ }_{150} \mathrm{UiO}-66$ and cal @ ${ }_{260} \mathrm{UiO}-66$, respectively, and with either transferrin or ceramide. In Fig. 5a, top, the yellow staining coming from the overlap of the green (i.e. calcein) and red (i.e. transferrin) fluorescence indicates a high correlation between the intracellular location of cal@ ${ }_{150} \mathrm{UiO}-66$ and clathrin-mediated vesicles, whereas in Fig. 5a, middle, only a small correlation between cal@ ${ }_{150}$ UiO-66 and caveolae-mediated (i.e. ceramide) vesicles is observed. Additionally, in Fig. 5a, bottom, a moderate degree of colocalization was observed for macropinocytosis (i.e. dextran). On the other hand, we also observed a high degree of co-localization between cal@ ${ }_{260}$ UiO-66 and clathrin-mediated (i.e. transferrin) vesicles (Fig. 5b), cal@ ${ }_{260} \mathrm{UiO}-66$ and caveolae-mediated (i.e. ceramide) vesicles and cal @ $260 \mathrm{UiO}$ 66 and macropinocytosis vesicles. We quantified these results by measuring the Manders' overlap coefficient (MOC), which varies from 0 for non-overlapping images to 1 , for complete colocalization (Figure 5c). ${ }^{[36,37]}$ The values obtained confirmed the higher degree of co-localization of cal@ ${ }_{150} \mathrm{UiO}-66$ and transferrin and dextran compared to ceramide, with values of $0.57,0.48$ and 0.15 , respectively. The analysis also proved the high correlation between cal @ ${ }_{260} \mathrm{UiO}-66$ and the three tracers, with values of $0.52,0.36$ and 0.37 for transferrin, ceramide and dextran, respectively. The small decrease $(10.5 \%)$ in the MOC when transferrin was incubated together with cal @ $260 \mathrm{UiO}$ 66 compared to cal@ ${ }_{150} \mathrm{UiO}-66$ showed no statistical significance. However, for ceramide, there was a substantial increment $(56.3 \%)$ in the MOC when it was incubated along cal @ ${ }_{260} \mathrm{UiO}-66$ in comparison to cal@ ${ }_{150} \mathrm{UiO}-66$. This further supports the fact that in the case of particles smaller than $200 \mathrm{~nm}$, clathrin-mediated endocytosis is preferred over caveolae-mediated pathway, whereas for particles larger than $200 \mathrm{~nm}$ the latter becomes also relevant. Finally, both particles are internalized non-specifically by macropinocytosis as shown in section 2.2. 

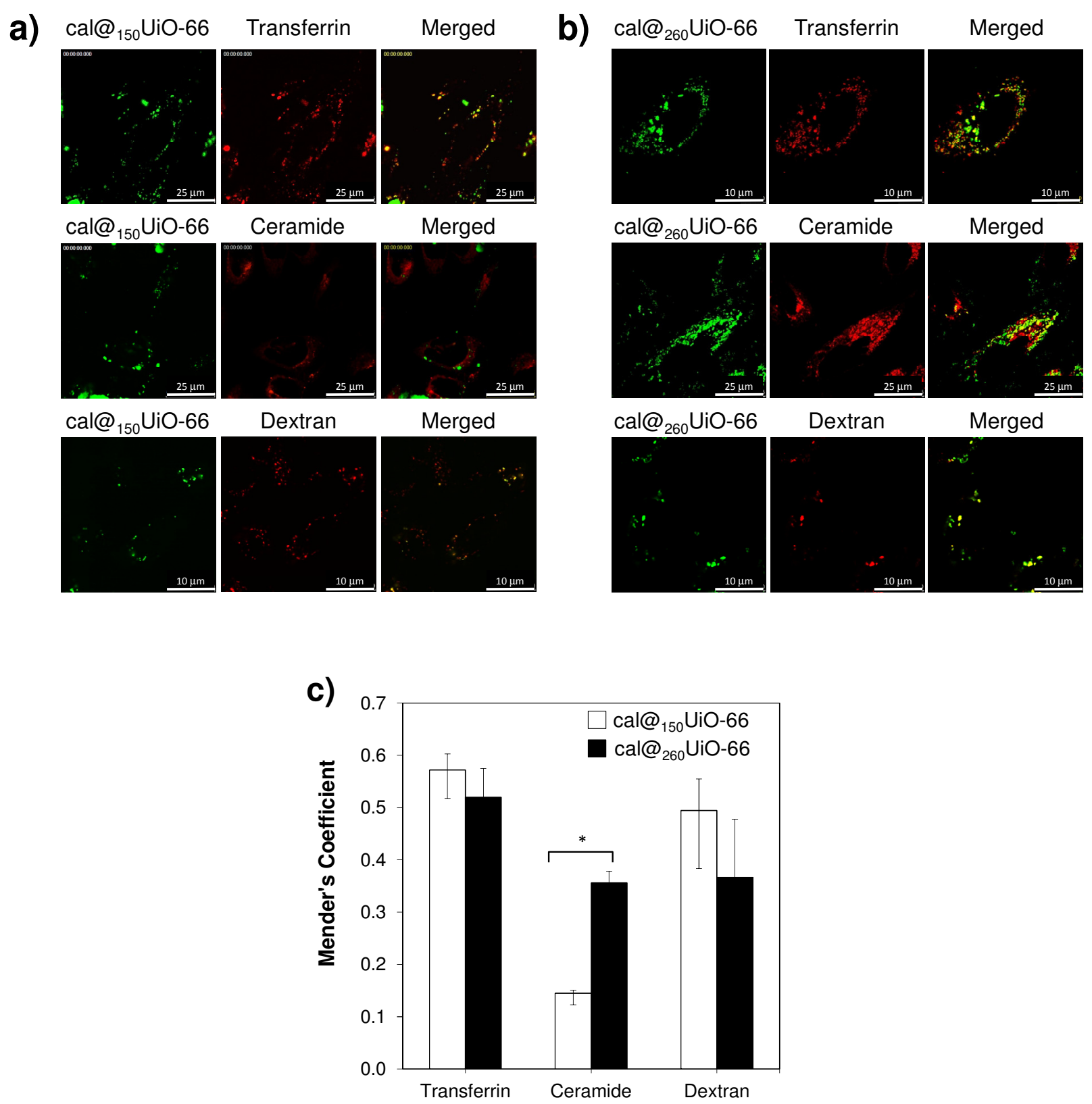

Figure 5. Confocal microscopy images of cells incubated with a) cal@ ${ }_{150} \mathrm{UiO}-66$, and b) cal @ $260 \mathrm{UiO}-66$, showing green fluorescence (i.e. calcein), and either transferrin (top, 100 $\mu \mathrm{g} / \mathrm{mL}$ ) or ceramide (bottom, $3.5 \mu \mathrm{g} / \mathrm{mL}$ ), showing red fluorescence. c) Mander's overlapping coefficient for both UiO-66s samples and tracers. Error bars represent the standard error of at least 10 independent images. 


\subsection{Effect of the internalization pathway on the final processing and fate of UiO-66}

After endocytosis occurs, the internalized drug delivery vehicle (i.e. the MOF particles) and drug molecules are processed via different metabolic pathways by transporting the vesicles to the correct intracellular organelle. ${ }^{[38]}$ It is believed that caveolae-mediated endocytosis vesicles, compared with the more classical clathrin-mediated, can avoid the lysosomes. ${ }^{[13]}$ This theory is based on pathogen studies, where some viruses and bacteria come into cells through this way bypassing the digestion in the lysosomes. ${ }^{[39]}$ Based on this idea, MOF particles should be internalized by the caveolaemediated pathway in order to avoid the lysosomal acidic degradation and to have a higher chance to deliver the cargo in other intracellular location without degradation. We therefore wanted to investigate the fate of the UiO-66 particles after the endocytosis process, and particularly whether the MOF particles were located in the lysosomes for further acidic degradation or not. In order to determine if the concentration of MOF affected the formation of lysosomes, we incubated the cells with different concentrations of empty ${ }_{150} \mathrm{UiO}-66$ and ${ }_{260} \mathrm{UiO}-66$, together with a lysosome marker (LysoTracker®-Deep red, Life Technologies). Figure 6 shows the confocal images of HeLa cells treated for $2 \mathrm{~h}$ with different concentrations of both UiO-66 samples, and then stained with LysoTracker®-Deep red. There was a significant increment in the number of lysosomes when the cells were incubated with $0.05 \mathrm{mg} / \mathrm{mL}$ of MOF compared with the control (i.e. cells incubated only with LysoTracker®-Deep red) for both ${ }_{150} \mathrm{UiO}-66$ and $260 \mathrm{UiO}-66$, something that was further intensified when the concentration was increased up to $0.5 \mathrm{mg} / \mathrm{mL}$, but was then stabilized at 1 $\mathrm{mg} / \mathrm{mL}$. Also, it was not possible to determine at this point differences between the two UiO-66 samples with different particle size. 


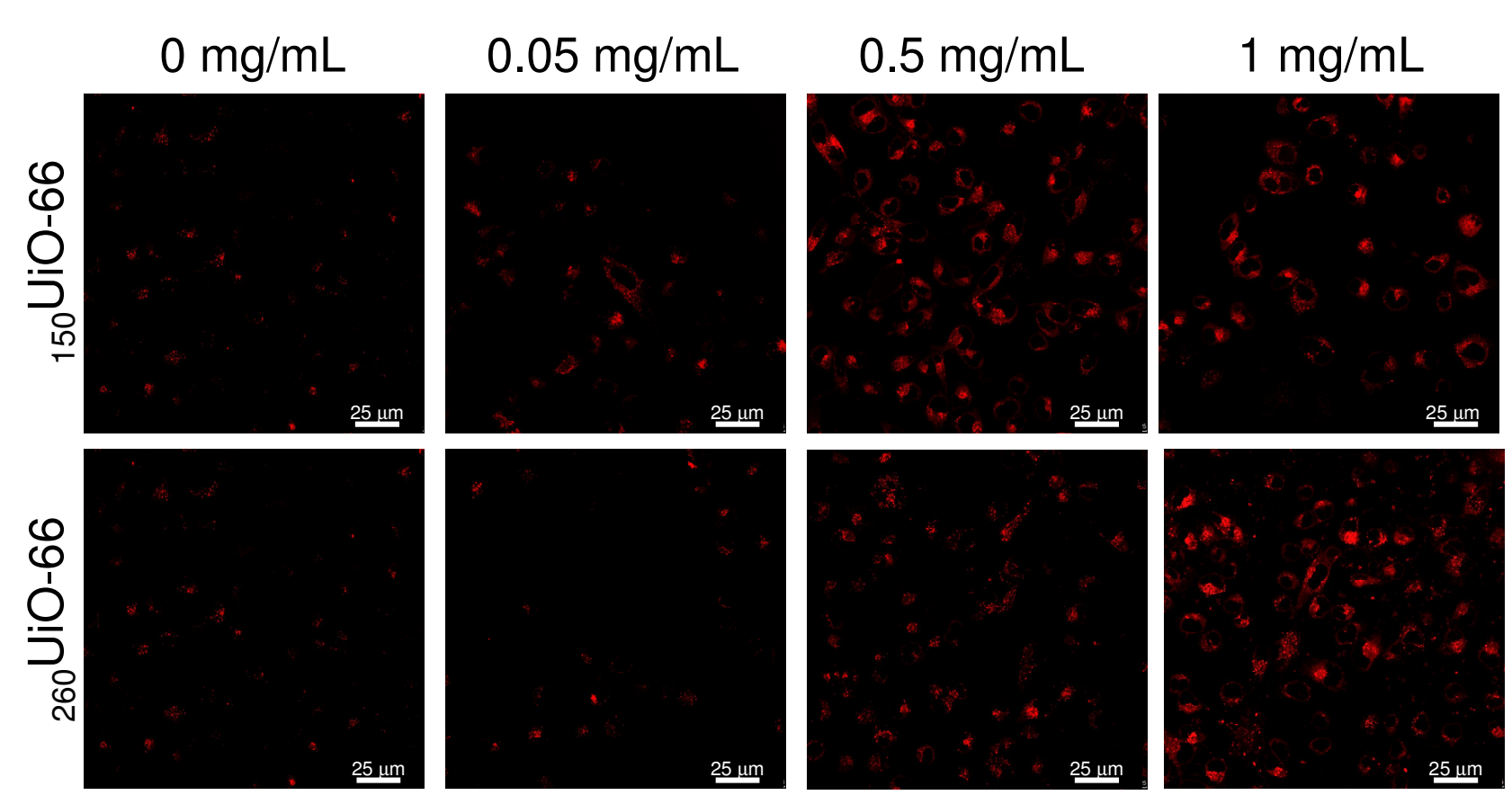

Figure 6. Effect of UiO-66 concentration in the formation of lysosomes. Confocal microscopy images of HeLa cells incubated for $2 \mathrm{~h}$ either with empty ${ }_{150} \mathrm{UiO}-66$ or ${ }_{260} \mathrm{UiO}-66$ and then for 30 min with LysoTracker®-Deep red (red fluorescence).

Figure $7 \mathrm{a}$ shows the confocal microscopy images used to carry out the co-localization studies, using LysoTracker@-Deep red, to determine the rate of both cal@UiO-66 samples located in the lysosome. After $2 \mathrm{~h}$ of incubation, we found a high level of co-localization between cal@ ${ }_{150}$ UiO-66 and LysoTracker®-Deep red, represented by the yellow color in the merged images, whereas we only found a moderate degree of correlation for cal@ ${ }_{260} \mathrm{UiO}-66$. Quantification analysis using the MOC confirmed these results. Indeed, the co-localization degree for cal @ ${ }_{260} \mathrm{UiO}-66$ was ca. $37 \%$ lower than for cal @ ${ }_{150} \mathrm{UiO}-66$, which indicates that later is located mostly in lysosomes for further degradation whereas cal @ $260 \mathrm{UiO}-66$ seems to successfully evade these compartments and potentially delivers cargo molecules in the cytosol. 

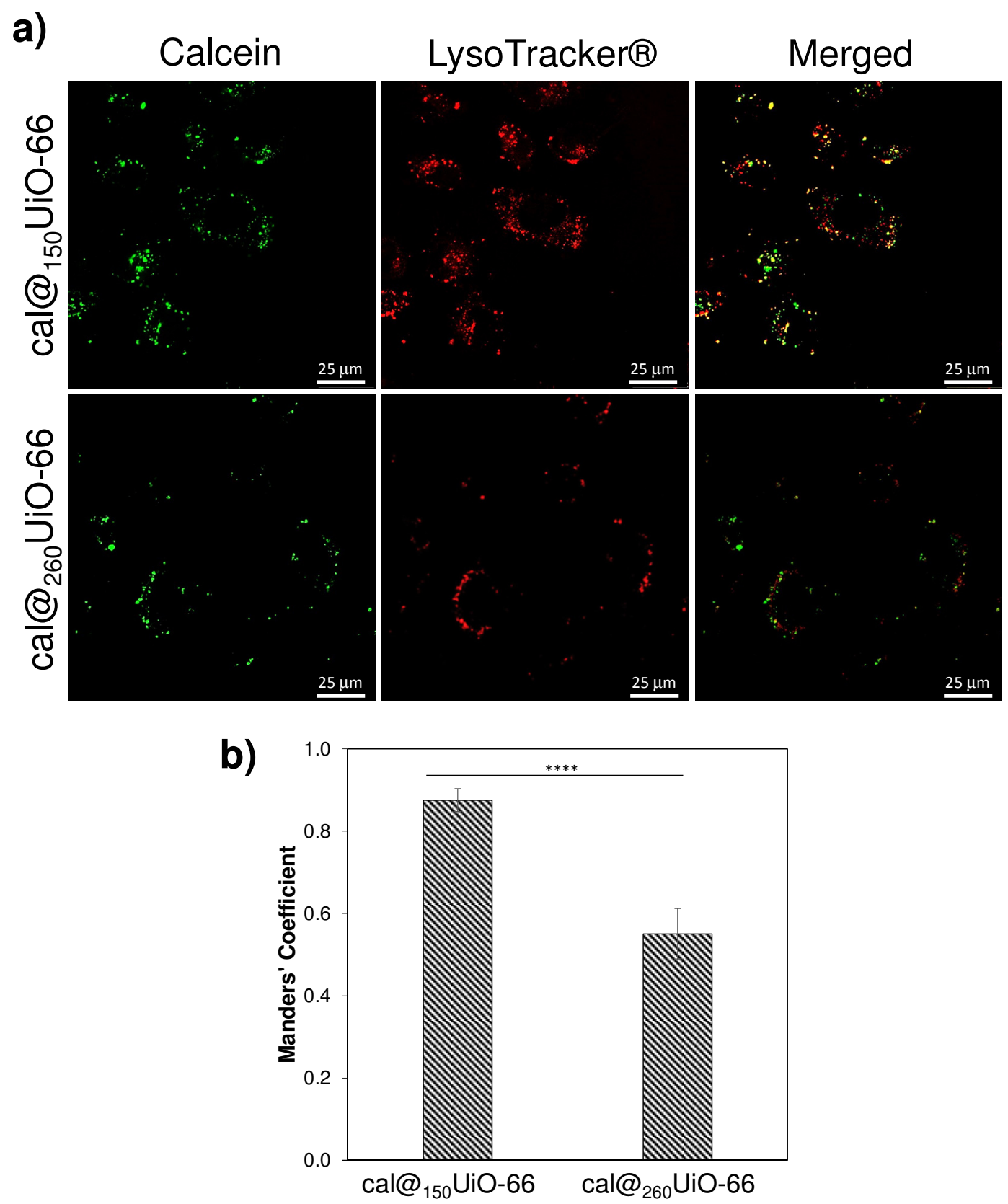

Figure 7. a) Confocal microscopy images of HeLa cells incubated with cal@ ${ }_{150} \mathrm{UiO}-66$ or cal@260UiO-66 (green fluorescence, i.e. calcein), and LysoTracker®-Deep red (red fluorescence), for $2 \mathrm{~h}$. b) Manders' overlapping coefficient for both UiO-66 samples and the lysosome marker. Error bars represent the standard error of at least 10 independent images.

Based on these results, it is possible that extremely small particle sized MOFs are not the most efficient carriers and instead, relatively medium size particles are required. Endosomal or lysosomal escape needs to be taken in account for the use of these materials in drug delivery application as particles trapped inside vesicles are not contributing to the final goal of delivering the cargo molecules in the cytosol. MOFs with special features that allow them to avoid or escape from 
the lysosome need to be developed as it has been done with other kind of nanoparticles. For example, Carregal-Romero et al. where able to synthesized particles that avoided the lysosomal degradation by NIR-light activated delivery. ${ }^{[40]}$ Also, some nanoparticles sensitive to $\mathrm{pH}$ have been shown to be able to deliver the guest molecules in the cytosol. ${ }^{[1,42]}$ Finally, these findings highlight the necessity of an in-depth study of particle characteristics, such particle size, external surface chemistry, and intracellular fate in the design of MOFs for drug delivery application.

\section{Conclusion}

In this work, we have studied the effect of particle size on the trafficking and subsequently processing of calcein loaded UiO-66 of two different sizes, 150 and $260 \mathrm{~nm}$, on HeLa cells. Our results show that cellular internalization of UiO-66 into HeLa cells is an energy dependent process and it is also determined by the particle size of the solids. Clathrin-mediated endocytosis was the preferred endocytic pathway for the smaller ${ }_{150} \mathrm{UiO}-66$ particles, whereas in the case of the larger ${ }_{260} \mathrm{UiO}-66$ particles, caveolae-mediated endocytosis became to play a more important role, and a combined pathway uptake was observed. Additionally, the internalization of the larger $260 \mathrm{UiO}-66$ particles was a more efficient - but slower - process compared with the uptake of the smaller 150UiO-66. More importantly, ${ }_{150} \mathrm{UiO}-66$ was localized mainly in lysosomes compared with larger UiO-66 particles, which seems to bypass them. This difference is critical when designing new MOF drug delivery systems since lysosome activity may prevent the MOF action before degradation. All these results stress the importance of studying the internalization process of nanocarriers and, more important, the final fate of them. In this work we have shown for the first time the importance of a balance between the size of MOFs for drug delivery in terms of efficiency, and where these particles end up inside cells, all in the efforts to increase the potential of MOFs for drug delivery applications. This contribution will allow selecting the optimal properties of MOFs in order to improve their efficiency for drug delivery. 


\section{Experimental Section}

Materials: $\mathrm{ZrCl}_{4}(99.5 \%)$ and terephthalic acid (98\%) were bought from Alfa Aesar (UK). Benzoic acid (99.5\%), $\mathrm{HCl}$ (37\%), Dimethylformamide (DMF, $99.8 \%)$ ), methanol (99.9\%), acetone $(99.9 \%)$, nystatin, sucrose $(99.5 \%)$, rottlerin, calcein disodium salt, were obtained from SigmaAldrich (UK). HeLa cells cells were obtained from the ATCC. Dulbecco's modified Eagle's medium (DMEM), foetal bovine serum (FBS), L-glutamine, penicillin, and streptomycin were purchased from Invitrogen (UK). Phosphate-Buffered Saline (PBS), trypsin-EDTA, transferrinAlexaFluor-633, BODIPY TR-ceramide, Texas Red-dextran, and Lysotracker®-Deep Red were purchased from Life Technologies ${ }^{\mathrm{TM}}$ (UK). The CellTiter 96® AQueous One Solution Cell Proliferation Assay (MTS) was obtained from Promega (UK). All chemicals and biochemicals used were of analytical grade.

Instruments: All PXRD data were collected in Bragg-Brentano geometry on a D8 Bruker diffractometer equipped with a primary $\mathrm{Ge}$ monochromator for $\mathrm{Cu} \mathrm{K} \alpha 1$ and a Sol-X solid state detector. Collection conditions were: $2-50^{\circ}$ in $2 \theta, 0.02^{\circ}$ step size, 15 seconds/step, divergence slits $0.2 \mathrm{~mm}$, receiving slit $0.2 \mathrm{~mm}$. Samples for SEM were scattered onto spectroscopically-pure carbon tabs (TAAB Ltd UK) mounted on aluminum stubs. They were coated with $15 \mathrm{~nm}$ of gold in a Quorum Emitech K575X sputter coater to make them electrically conductive. They were imaged in an FEI XL30 FEGSEM, operated at $5 \mathrm{keV}$, using an Everhart Thornley secondary electron detector. Colloidal analysis was determined by dynamic light scattering (DLS) with a Brookhaven Zeta Plus potential analyzer (detection angle of $90^{\circ}$ and a $35 \mathrm{~mW}$ laser). The measurements were performed in phosphate-buffered saline (PBS) and growth media at room temperature. Thermogravimetric analysis (TGA) was performed using a TA Instruments Q-500 series thermal gravimetric analyzer, with the sample $(0.7-2 \mathrm{mg})$ held on a platinum pan under a continuous flow of dry $\mathrm{N}_{2}$ gas. TGA curves were obtained using a heating rate of $5^{\circ} \mathrm{C} / \mathrm{min}$ and up to $600{ }^{\circ} \mathrm{C}$.

Synthesis and characterization: ${ }_{150} \mathrm{UiO}-66$ was obtain following the protocol from Zhu et al., ${ }^{[22]}$ where $466 \mathrm{mg}$ of $\mathrm{ZrCl}_{4}, 320 \mathrm{mg}$ of terephthalic acid (BDC), $2.44 \mathrm{~g}$ of benzoic acid and $0.33 \mathrm{~mL}$ of 
$\mathrm{HCl} 37 \%$ were dissolved in $36 \mathrm{~mL}$ of DMF. The mixture was placed in a $50 \mathrm{~mL}$ autoclave and heated at $120{ }^{\circ} \mathrm{C}$ for $48 \mathrm{~h}$. After cooling down to room temperature, a white powder of UiO-66 was harvested by centrifugation at $5500 \mathrm{rpm}$ for $20 \mathrm{~min}$ and washed with DMF at room temperature. The particles were then dispersed and washed with DMF in order to remove the non-reacted BDC. The same procedure was repeated with acetone and then with methanol in order to remove the DMF solvent from the sample. Finally, the solids were dried at $80^{\circ} \mathrm{C}$ in a vacuum oven overnight.

${ }_{260} \mathrm{UiO}-66$ was obtained following the procedure described by Katz et al., ${ }^{[27]}$ where $0.125 \mathrm{~g}$ of $\mathrm{ZrCl}_{4}$ were dissolved in $5 \mathrm{ml}$ of DMF and $1 \mathrm{ml}$ of $\mathrm{HCl}(37 \%)$, while $0.123 \mathrm{~g}$ of terephthalic acid (BDC) were dissolved in $10 \mathrm{ml}$ of DMF. The two solutions were mixed in a $25 \mathrm{ml}$ teflon lined autoclave and heated at $80{ }^{\circ} \mathrm{C}$ for 16 hours. The resulting solid was collected by centrifugation at $5500 \mathrm{rpm}$ for 10 minutes and then washed with DMF at room temperature. The particles were then dispersed and washed with DMF in order to remove the non-reacted BDC. The same procedure was repeated with acetone and then with methanol in order to remove the DMF solvent from the sample. Finally, the solids were dried at $80{ }^{\circ} \mathrm{C}$ in a vacuum oven overnight.

Calcein loading experiments: Calcein adsorption was performed by soaking $100 \mathrm{mg}$ of activated UiO-66 into $40 \mathrm{~mL}$ of methanol calcein solution $(5 \mathrm{mg} / \mathrm{mL})$ at $37{ }^{\circ} \mathrm{C}$ under orbital agitation for 4 days. The loaded material was collected by centrifugation at $5500 \mathrm{rpm}$ for 20 minutes, washed twice with methanol, centrifuged again for 10 minutes and dried overnight at $37^{\circ} \mathrm{C}$ to remove the solvent. The amount of calcein adsorbed was quantified by thermogravimetric analysis (TGA).

Cell culture: HeLa cells were maintained at $37^{\circ} \mathrm{C}$ with $5 \% \mathrm{CO}_{2}$ in high rich glucose $(4500 \mathrm{mg} / \mathrm{L})$ Dulbecco's modified Eagle's Medium (DMEM) with phenol red supplemented with $10 \%$ (v/v) Fetal Bovine Serum (FBS), $2 \mathrm{mM}$ L-glutamine, 100 units $/ \mathrm{mL}$ penicillin and $100 \mu \mathrm{g} / \mathrm{mL}$ streptomycin. This was named complete DMEM (cDMEM). The cells were passaged three times a week (at 75-80 $\%$ of confluence) at a density of $2.8 \times 104$ cell $/ \mathrm{cm}^{2}$.

Cytotoxicity assays: The cytotoxicity activity of the inhibitors was investigated using the 3-(4, 5dimethylthiazol-2-yl)-5-(3- carboxymethoxyphenyl)-2-(4-sulfophenyl)-2H-tetrazolium 
(Promega, UK) reduction assay. The day before the experiment, cells were seeded into a 96 well plate at a density of $5 \times 10^{3}$ cells per well. Prior to the treatments, cells were washed twice with PBS. The inhibitors were dissolved in cDMEM at different concentrations. They were then added to the cells and incubated for $2 \mathrm{~h}$ at $37{ }^{\circ} \mathrm{C}$ with $5 \% \mathrm{CO}_{2}$. To measure the toxicity, the cells were washed three times with PBS, the media was replaced with $100 \mu \mathrm{l}$ of fresh culture media containing $20 \mu \mathrm{l}$ of MTS/phenazine methosulfate (in a proportion 20:1) solution, and the plate was incubated for $1 \mathrm{~h}$ at $37^{\circ} \mathrm{C}$ with $5 \% \mathrm{CO}_{2}$. The plates were read at $490 \mathrm{~nm}$.

Flow cytometry assays (FACS): In all the FACS experiments, after any treatment, the media of each well was aspirated and the wells were washed extensively to remove all the conditions. The cells were then harvested by adding $0.1 \mathrm{~mL}$ of trypsin and incubated for $5 \mathrm{~min}$ at $37{ }^{\circ} \mathrm{C}$ with $5 \% \mathrm{CO}_{2}$. The cells were recovered by centrifugation, $5 \mathrm{~min}$ at $1200 \mathrm{rpm}$, and re-suspended in $100 \mu \mathrm{l}$ of cDMEM without phenol red. Finally the samples were measure in a Cytek DxP8 analyzer cytometer within $30 \mathrm{~min}$. The analysis of the data was done using FlowJo and Prism software.

Energy dependence assay: HeLa cells were seeded in a Cellstar 24-well plate at a density of $5 \times 10^{4}$ cell/well and incubated for $48 \mathrm{~h}$ at $37{ }^{\circ} \mathrm{C}$ with $5 \% \mathrm{CO}_{2}$ in cDMEM. Then, each well was washed with PBS and pre-treated at either at 4 or $37{ }^{\circ} \mathrm{C}$ (control) for $30 \mathrm{~min}$. After this period, either cal@ ${ }_{150}$ UiO-66 or cal@ ${ }_{260}$ UiO-66 where added and incubated for 1.5 h. Subsequently, samples were measured by flow cytometry.

Treatment with inhibitors: HeLa cells were seeded in a Cellstar 24-well plate at a density of $5 \times 10^{4}$ cell/well and incubated for $48 \mathrm{~h}$ at $37{ }^{\circ} \mathrm{C}$ with $5 \% \mathrm{CO}_{2}$ in cDMEM. Then, each well was washed with PBS and pre-treated with sucrose $(102.7 \mathrm{mg} / \mathrm{mL}, 0.3 \mathrm{M})$, chlorpromazine $(31.9 \mu \mathrm{g} / \mathrm{mL}, 100$ $\mu \mathrm{M})$, nystatin $(250 \mu \mathrm{g} / \mathrm{mL})$, and rottlerin $(2.6 \mu \mathrm{g} / \mathrm{mL}, 5 \mu \mathrm{M})$ for $30 \mathrm{~min}$ at $37{ }^{\circ} \mathrm{C}$. Subsequently, either cal@ ${ }_{150} \mathrm{UiO}-66$, cal@ ${ }_{260} \mathrm{UiO}-66$ or endocytosis tracers (transferrin-AlexaFluor-633, 25 $\mu \mathrm{g} / \mathrm{mL}$; BODIPY TR-ceramide, $3.5 \mu \mathrm{g} / \mathrm{mL}$; and Texas Red-dextran-10kDa, $0.5 \mathrm{mg} / \mathrm{mL}$ ) were added and incubated for another $1.5 \mathrm{~h}$. Subsequently, samples were measured by flow cytometry. 
Kinetics of cal@UiO-66 uptake: HeLa cells were seeded in a Cellstar 24-well plate at a density of 5 x $10^{4}$ cell/well and incubated for $48 \mathrm{~h}$ at $37{ }^{\circ} \mathrm{C}$ with $5 \% \mathrm{CO}_{2}$ in cDMEM. Then, each well was washed with PBS and incubated with $0.5 \mathrm{mg} / \mathrm{mL}$ and $0.35 \mathrm{mg} / \mathrm{mL}$ of cal @ ${ }_{150} \mathrm{UiO}-66$ and cal $@_{260} \mathrm{UiO}-66$ respectively for different times. Subsequently, samples were measured by flow cytometry.

Lysosome formation analysis: HeLa cells were seeded in a $\mathrm{NUNC}^{\mathrm{TM}}$ imaging four-well plate at a density of $1.11 \times 105$ cell/mL and incubated for $24 \mathrm{~h}$ at $37^{\circ} \mathrm{C}$ with $5 \% \mathrm{CO}_{2}$ in cDMEM. The cells were then washed with PBS and incubated with $0.05,0.5$ and $1 \mathrm{mg} / \mathrm{mL}$ of empty ${ }_{150} \mathrm{UiO}-66$ or ${ }_{260} \mathrm{UiO}-66$ for $2 \mathrm{~h}$ at $37^{\circ} \mathrm{C}$ with $5 \% \mathrm{CO}_{2}$ in cDMEM. Subsequently, cells were washed with PBS to remove the conditions and incubated with LysoTracker®-Deep red for another $30 \mathrm{~min}$. Then, the cells were washed with trypan blue $(0.4 \%)$ to quench any external fluorescence and three times with PBS. Then, fresh media without phenol red was added to each sample. Finally, the four-well plate was placed on a Leica TCS SP5 confocal microscope to be imaged. The microscope was equipped with 405 diode, argon and HeNe lasers. Leica LAS AF software was used to analyze the images.

Co-localization experiments: For all the co-localization experiments HeLa cells were seeded in a $\mathrm{NUNC}^{\mathrm{TM}}$ imaging four-well plate at a density of $1.11 \times 105$ cell/mL and incubated for $24 \mathrm{~h}$ at $37^{\circ} \mathrm{C}$ with $5 \% \mathrm{CO}_{2}$ in cDMEM. At the end the four-well plate was placed on a Leica TCS SP5 confocal microscope to be imaged. The microscope was equipped with 405 diode, argon and HeNe lasers. Leica LAS AF software was used to analyze the images. To quantify co-localization a minimum of 4 and a maximum of 7 images were analyzed from each experiment. The images were analyzed using a co-localization plug-in on Image $\left(\mathrm{JaCOP}^{[41]}\right)$.

Tracers: The cells were then washed with PBS and incubated with $0.5 \mathrm{mg} / \mathrm{mL}$ of cal @ ${ }_{150} \mathrm{UiO}-66$ or $0.35 \mathrm{mg} / \mathrm{mL}$ of cal $@_{260} \mathrm{UiO}-66$ along with either transferrin $(100 \mu \mathrm{g} / \mathrm{mL})$, ceramide $(3.5 \mu \mathrm{g} / \mathrm{mL})$ or dextran-10 $\mathrm{kDa}(0.5 \mathrm{mg} / \mathrm{mL})$ for another $24 \mathrm{~h}$ at $37{ }^{\circ} \mathrm{C}$ with $5 \% \mathrm{CO}_{2}$ in cDMEM. Subsequently, the cells were washed with PBS to remove the conditions, with trypan blue $(0.4 \%)$ to quench any 
external fluorescence, and again three times with PBS. Finally, fresh cDMEM without phenol red was added to each sample.

LysoTracker®-Deep red: The cells were then washed with PBS and incubated with $0.5 \mathrm{mg} / \mathrm{mL}$ of cal@ ${ }_{150} \mathrm{UiO}-66$ or $0.35 \mathrm{mg} / \mathrm{mL}$ of cal @ ${ }_{260} \mathrm{UiO}-66$ along with LysoTracker@-Deep red for $2 \mathrm{~h}$ at 37 ${ }^{\circ} \mathrm{C}$ with $5 \% \mathrm{CO}_{2}$ in cDMEM. Subsequently, the cells were washed with PBS to remove the conditions, with trypan blue $(0.4 \%)$ to quench any external fluorescence, and again three times with PBS. Finally, fresh media without phenol red was added to each sample.

\section{Supporting Information}

Supporting Information is available from the Wiley Online Library or from the author.

\section{Acknowledgements}

C.A.O. and S.M. thank Becas Chile and the Cambridge Trust for funding. D.F.-J. thanks the Royal Society (UK) for funding through a University Research Fellowship.

Received: ((will be filled in by the editorial staff))

Revised: ((will be filled in by the editorial staff)) Published online: ((will be filled in by the editorial staff))

[1] S. M. Moghimi, A. C. Hunter, J. C. Murray, FASEB J. 2005, 19, 311.

[2] J. Della Rocca, D. Liu, W. Lin, Acc. Chem. Res. 2011, 44, 957.

[3] M. E. Davis, Z. G. Chen, D. M. Shin, Nat. Rev. Drug Discov. 2008, 7, 771.

[4] H. Furukawa, K. E. Cordova, M. O’Keeffe, O. M. Yaghi, Science 2013, 341, 1230444.

[5] P. Horcajada, R. Gref, T. Baati, P. K. Allan, G. Maurin, P. Couvreur, G. Férey, R. E. Morris, C. Serre, Chem. Rev. 2012, 112, 1232.

[6] A. C. McKinlay, B. Xiao, D. S. Wragg, P. S. Wheatley, I. L. Megson, R. E. Morris, J. Am. Chem. Soc. 2008, 130, 10440.

[7] C. He, K. Lu, D. Liu, W. Lin, J. Am. Chem. Soc. 2014, 136, 5181.

[8] P. Horcajada, T. Chalati, C. Serre, B. Gillet, C. Sebrie, T. Baati, J. F. Eubank, D. Heurtaux, P. Clayette, C. Kreuz, J.-S. Chang, Y. K. Hwang, V. Marsaud, P.-N. Bories, L. Cynober, S. Gil, G. Férey, P. Couvreur, R. Gref, Nat. Mater. 2010, 9, 172.

[9] E. Bellido, T. Hidalgo, M. V. Lozano, M. Guillevic, R. Simón-Vázquez, M. J. SantanderOrtega, Á. González-Fernández, C. Serre, M. J. Alonso, P. Horcajada, Adv. Healthc. Mater. 2015, 4, 1246.

[10] M. C. Bernini, D. Fairen-Jimenez, M. Pasinetti, A. J. Ramirez-Pastor, R. Q. Snurr, J. Mater. Chem. B 2014, 2, 766.

[11] J. I. Jin-gou, Z. Jing-fen, H. A. O. Shi-lei, W. U. Dan-jun, L. I. U. Li, X. U. Yi, Chem. Res. 
Chinese Univ. 2012, 28, 166.

[12] C. Orellana-Tavra, E. F. Baxter, T. Tian, T. D. Bennett, N. K. H. Slater, A. K. Cheetham, D. Fairen-Jimenez, Chem. Commun. 2015, 51, 13857.

[13] L. Kou, J. Sun, Y. Zhai, Z. He, Asian J. Pharm. Sci. 2013, 8, 1.

[14] S. Mayor, R. E. Pagano, Nat. Rev. Mol. Cell Biol. 2007, 8, 603.

[15] T.-G. Iversen, T. Skotland, K. Sandvig, Nano Today 2011, 6, 176.

[16] J. H. Park, N. Oh, Int. J. Nanomedicine 2014, 51.

[17] B. D. Chithrani, A. a. Ghazani, W. C. W. Chan, Nano Lett. 2006, 6, 662.

[18] K. Y. Win, S.-S. Feng, Biomaterials 2005, 26, 2713.

[19] I. Mellman, Annu. Rev. Cell Dev. Biol. 1996, 12, 575.

[20] J. Rejman, V. Oberle, I. S. Zuhorn, D. Hoekstra, Biochem. J. 2004, 377, 159.

[21] X. Zhu, J. Gu, Y. Wang, B. Li, Y. Li, W. Zhao, J. Shi, Chem. Commun. 2014, 1.

[22] D. Cunha, M. Ben Yahia, S. Hall, S. R. Miller, H. Chevreau, E. Elka, G. Maurin, P. Horcajada, C. Serre, Chem. Mater. 2013.

[23] 2012. Zirconium and its compounds [MAK Value Documentation 1999], The MAKCollection for Occupational Health and Safety, Wiley-VCH Verlag GmbH \& Co. KGaA, Weinheim, Germany, 2002.

[24] D. Cunha, C. Gaudin, I. Colinet, P. Horcajada, G. Maurin, C. Serre, J. Mater. Chem. B 2013, 1,1101 .

[25] J. H. Cavka, S. Jakobsen, U. Olsbye, N. Guillou, C. Lamberti, S. Bordiga, K. P. Lillerud, J. Am. Chem. Soc. 2008, 130, 13850.

[26] M. J. Katz, Z. J. Brown, Y. J. Colón, P. W. Siu, K. A. Scheidt, R. Q. Snurr, J. T. Hupp, O. K. Farha, Chem. Commun. 2013, 49, 9449.

[27] M. Javadi, W. G. Pitt, C. M. Tracy, J. R. Barrow, B. M. Willardson, J. M. Hartley, N. H. Tsosie, J. Control. Release 2013, 167, 92.

[28] S. Khormaee, Y. Choi, M. J. Shen, B. Xu, H. Wu, G. L. Griffiths, R. Chen, N. K. H. Slater, J. K. Park, Adv. Funct. Mater. 2013, 23, 1.

[29] K. Shapero, F. Fenaroli, I. Lynch, D. C. Cottell, A. Salvati, K. a Dawson, Mol. BioSyst. 2011, 7, 371 .

[30] T. dos Santos, J. Varela, I. Lynch, A. Salvati, K. a. Dawson, PLoS One 2011, 6, e24438.

[31] A. I. Ivanov, in Exocytosis and Endocytosis, 2008.

[32] K. Sarkar, M. J. Kruhlak, S. L. Erlandsen, S. Shaw, Immunology 2005, 116, 513.

[33] S. M. Stamatovic, R. F. Keep, M. M. Wang, I. Jankovic, A. V Andjelkovic, J. Biol. Chem. 2009, 284, 19053.

[34] R. D. Singh, Mol. Biol. Cell 2003, 14, 3254.

[35] J. P. Lim, P. a Gleeson, Immunol. Cell Biol. 2011, 89, 836.

[36] J. A. Manders, E. M. M., Verbeek, F. J., Aten, J. Microsc. 1993, 169, 375.

[37] S. Bolte, F. P. Cordelieres, J. Microsc. 2006, 224, 213. 
[38] C. T. Okamoto, Adv. Drug Deliv. Rev. 1998, 29, 215.

[39] J. S. Shin, S. N. Abraham, Microbes Infect. 2001, 3, 755.

[40] S. Carregal-Romero, M. Ochs, P. Rivera-Gil, C. Ganas, A. M. Pavlov, G. B. Sukhorukov, W. J. Parak, J. Control. Release 2012, 159, 120.

[41] A. Kichler, J. Gene Med. 2004, 6, 3.

[42] D. C. Drummond, M. Zignani, J. C. Leroux, Prog. Lipid Res. 2000, 39, 409. 
The study of the uptake mechanism and final fate of a promising metal-organic framework (MOF) is a crucial step for optimizing these materials for drug delivery applications. UiO-66 particles of $260 \mathrm{~nm}$ are able of partially bypass the acidic degradation in the lysosomes whereas particles of $150 \mathrm{~nm}$ are destroyed in this compartment.

Keyword: drug delivery, metal-organic frameworks, endocytosis

C. Orellana-Tavra, S. A. Mercado and D. Fairen-Jimenez*

Endocytosis Mechanisms of Nano Metal-organic Frameworks for Drug Delivery

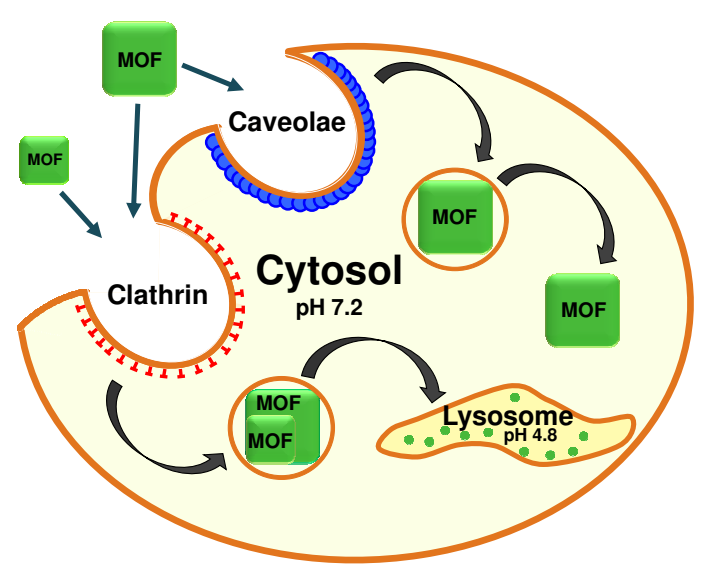


Copyright WILEY-VCH Verlag GmbH \& Co. KGaA, 69469 Weinheim, Germany, 2013.

Supporting Information for:

\section{Endocytosis Mechanisms of Nano Metal-organic Frameworks for Drug Delivery}

C. Orellana-Tavra, S. A. Mercado and D. Fairen-Jimenez*

Department of Chemical Engineering \& Biotechnology, University of Cambridge, CB2 3RA Cambridge. E-mail: df334@cam.ac.uk

\section{Contents}

S1. Powder X-Ray Diffraction (PXRD) S1

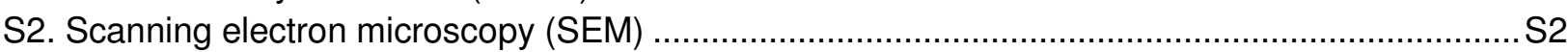

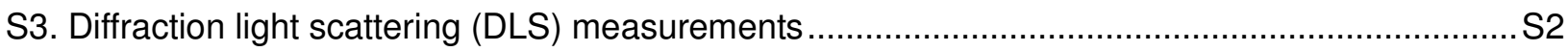

S4. Thermogravimetric analysis (TGA) S3

S1. Powder X-Ray Diffraction (PXRD)

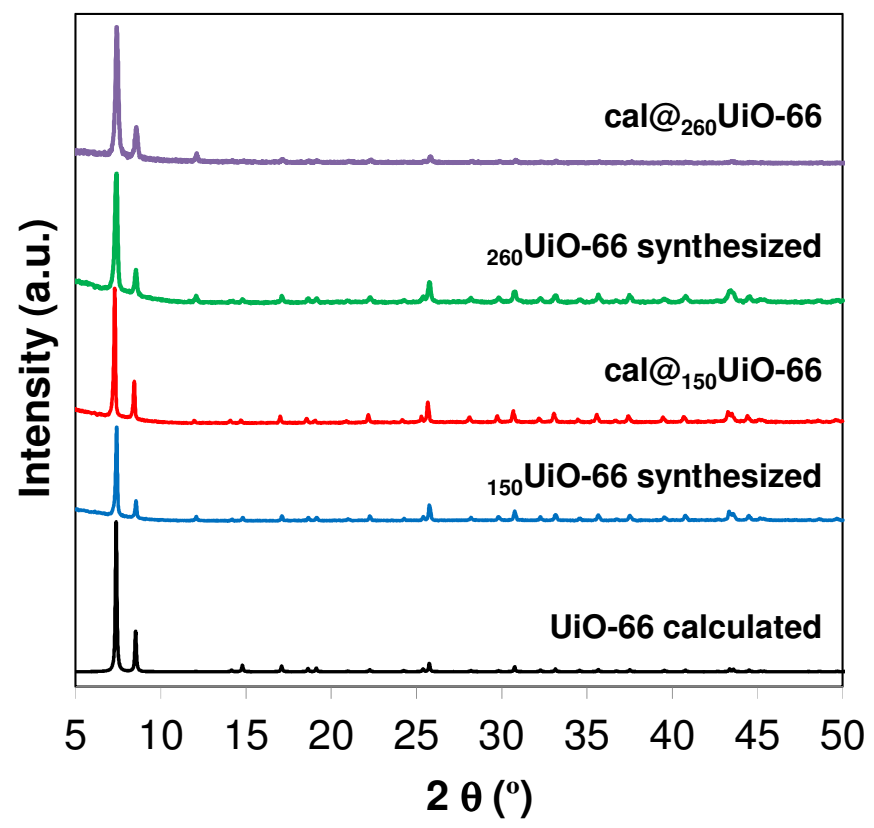

Figure S1. Powder X-ray diffraction (PXRD) patterns of synthesized ${ }_{150} \mathrm{UiO}-66$ and ${ }_{260} \mathrm{UiO}-66$, cal@ ${ }_{150} \mathrm{UiO}-66$ and cal@ $@_{260} \mathrm{UiO}-66$ compared with the calculated one for UiO-66. 


\section{S2. Scanning electron microscopy (SEM)}

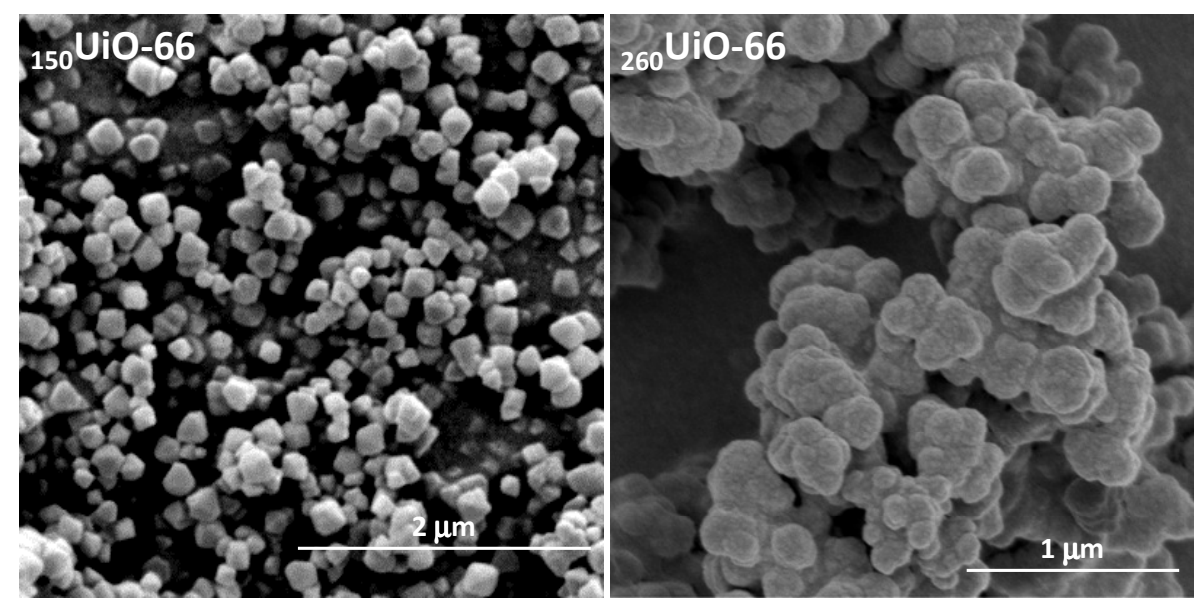

Figure S2. SEM images for a) ${ }_{150} \mathrm{UiO}-66$, and b) $260 \mathrm{UiO}-66$.

\section{S3. Diffraction light scattering (DLS) measurements}

It is possible to see from figure $\mathrm{S} 3$ that the material of both particles sizes aggregates more when is in PBS solution compared with the values in growth media. This less aggregation is probably the result of the interaction of the material with proteins present in growth media and not in PBS.

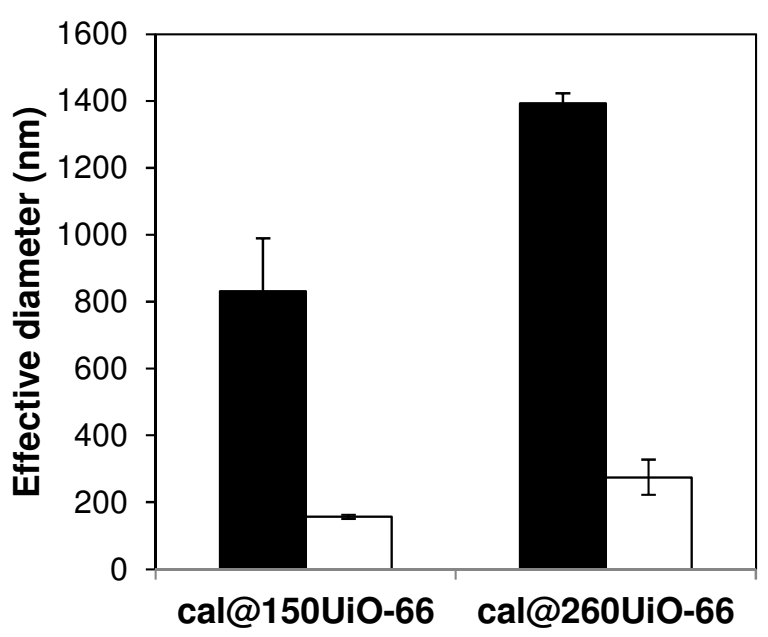

Figure S3. Particle size analysis images for: PBS (black), and growth media (white). 


\section{S4. Thermogravimetric analysis (TGA)}

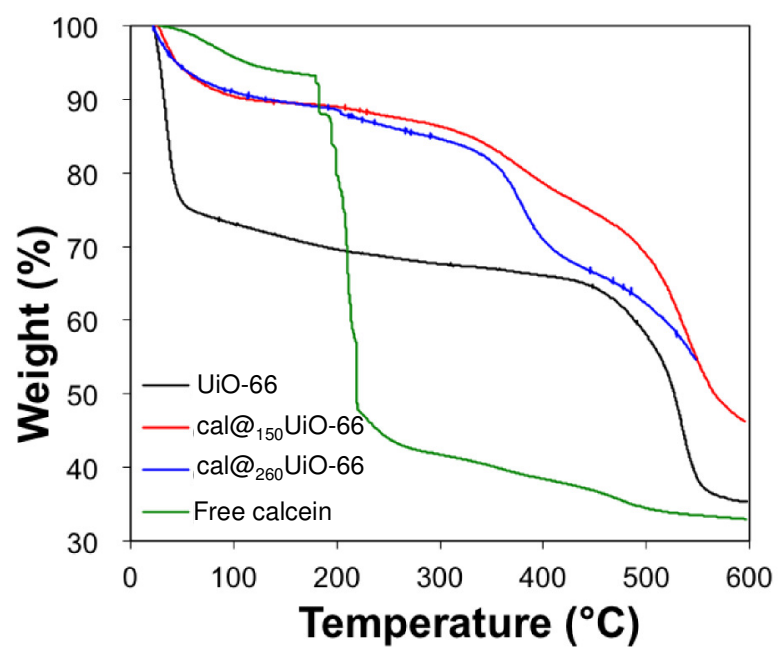

Figure S4. TGA curves under dry $\mathrm{N}_{2}$ gas of UiO-66, black solid line; cal@ $@_{150} \mathrm{UiO}-66$, red solid line; cal@ ${ }_{150} \mathrm{UiO}_{\mathrm{O}}-66$, blue solid line; and free calcein, green solid line. 